\title{
Monoclonal human IgGs capable of neutralizing elapid neurotoxins in vivo
}

\author{
Pus, Urska; Laustsen, Andreas Hougaard; Karatt-Vellatt, Aneesh; Griffiths, Daniel T.; Oscoz, Saioa; \\ Andersen, Mikael Rørdam; Harrison, Robert; Casewell, Nicholas; Lomonte, Bruno; McCafferty, John \\ Total number of authors: \\ 11
}

Published in:

Toxicon

Link to article, DOI:

10.1016/j.toxicon.2018.10.154

Publication date:

2019

Document Version

Publisher's PDF, also known as Version of record

Link back to DTU Orbit

Citation (APA):

Pus, U., Laustsen, A. H., Karatt-Vellatt, A., Griffiths, D. T., Oscoz, S., Andersen, M. R., Harrison, R., Casewell, N., Lomonte, B., McCafferty, J., \& Gutiérrez, J. M. (2019). Monoclonal human IgGs capable of neutralizing elapid neurotoxins in vivo. Toxicon, 158(Suppl. 1), S44-S44. [145]. https://doi.org/10.1016/j.toxicon.2018.10.154

\section{General rights}

Copyright and moral rights for the publications made accessible in the public portal are retained by the authors and/or other copyright owners and it is a condition of accessing publications that users recognise and abide by the legal requirements associated with these rights.

- Users may download and print one copy of any publication from the public portal for the purpose of private study or research.

- You may not further distribute the material or use it for any profit-making activity or commercial gain

- You may freely distribute the URL identifying the publication in the public portal 
Silvia L. Saggiomo*, Jamie Seymour. Australian Institute of Tropical Health and Medicine, James Cook University, McGregor Road, Cairns, QLD 4878, Australia

* Corresponding author.

E-mail address: silvia.saggiomo@my.jcu.edu.au (S.L. Saggiomo).

\section{Abstract}

Cubozoans include jellyfish that range from the most venomous animal on the planet, through small jellyfish that cause Irukandji Syndrome to others that have no effects on humans. These animals have a massive negative effect on Australian (and worldwide) tourism, with the annual cost to Queensland health alone being over 15 million dollars annually. In some species, the venom is known to be cardiac specific. We determined the venom effects using a live animal model with real time cardiac monitoring. Two species of box jellyfish were used, namely Chironex fleckeri and Carukia barnesi. Cardiac output was measured (including aortic and mitral outflows) through a doppler monitoring system. We discuss the implications of these results in terms of first aid management.

Keywords: jellyfish venom, Chironex fleckeri, Carukia barnesi, cardiophysiology, first aid

145

\section{MONOCLONAL HUMAN IGGS CAPABLE OF NEUTRALIZING ELAPID} NEUROTOXINS IN VIVO

Urska Pus ${ }^{\mathrm{a},{ }^{*}}$, Andreas H. Laustsen ${ }^{\mathrm{a}}$, Aneesh Karatt-Vellatt ${ }^{\mathrm{b}}$, Daniel T. Griffiths $^{\mathrm{b}}$, Saioa Oscoz ${ }^{\mathrm{d}}$, Mikael R. Andersen ${ }^{\mathrm{a}}$, Robert Harrison ${ }^{c}$, Nicholas Casewell ${ }^{c}$, Bruno Lomonte ${ }^{\mathrm{d}}$, John McCafferty ${ }^{\mathrm{b}}$, José María Gutiérrez ${ }^{\mathrm{d}}$. ${ }^{\mathrm{a}}$ Department of Biotechnology and Biomedicine, Technical University of Denmark, Kongens Lyngby, Denmark; ' ${ }^{\mathrm{b}}$ IONTAS, Iconix Park, London Road, Pampisford, Cambridge, CB223EG, United Kingdom; ' ${ }^{\mathrm{C}}$ Alistair Reid Venom Research Unit, Liverpool School of Tropical Medicine, Liverpool, United Kingdom; ${ }^{\mathrm{d}}$ Instituto Clodomiro Picado, Facultad de Microbiología, Universidad de Costa Rica, San José, Costa Rica

* Corresponding author.

E-mail address: pus.urska@gmail.com (U. Pus).

\section{Abstract}

The two elapids, the black mamba (Dendroaspis polylepis) and the monocled cobra (Naja kaouthia) are notorious for their bite, which each year causes a substantial share of the severe envenomings that occur in subSaharan Africa and Southeast Asia, respectively. Through a combined toxicovenomics and the phage display selection approach, monoclonal fully human IgGs were discovered and assessed for their ability to neutralize medically relevant toxins from the aforementioned snakes in vivo. The discovered monoclonal human IgGs were expressed in mammalian Expi-293 cells and tested in CD-1 mice using two different routes of administration. Initially, IgGs were incubated for $30 \mathrm{~min}$ at $37^{\circ} \mathrm{C}$ together with their target toxins in different molar ratios (mol toxin: mol IgG of $1: 3$ to $1: 8$ ) and then administered either intracerebroventricularly (i.c.v.) (dendrotoxins) using a toxin dose of $0.5 \mu$ g or intravenously (i.v.) ( $\alpha$ cobratoxin) using a toxin dose of $4 \mu \mathrm{g}$ to evaluate the neutralization potential of the IgGs. The survival of mice administered with lethal doses of elapid toxins was substantially prolonged by the monoclonal human IgGs. Hence, we report the discovery of monoclonal fully human IgGs that are able to neutralize snake toxins in vivo. Additionally, one of the tested human IgGs was able to prolong survival both against its cognate toxin $(\alpha-$ cobratoxin) and against whole venom from $N$. kaouthia. This demonstrates the applicability of the Toxicity Score for identifying medically relevant toxins in a venom and that $\alpha$-cobratoxin is one of the key toxic components of $N$. kaouthia venom.

Keywords: Recombinant antivenom, Black mamba, Monocled cobra, Monoclonal human IgG

146

CHARACTERISATION OF PREDICTED HELICAL REGIONS IN THE CHIRONEX FLECKERI CFTX-1 TOXIN
Athena Andreosso, Paramjit S. Bansal, Michael J. Smout, David Wilson, Jamie E. Seymour, Norelle L. Daly*. Centre for Biodiscovery and Molecular Development of Therapeutics, AITHM, James Cook University, Cairns, QLD, Australia

* Corresponding author

E-mail address: norelle.daly@jcu.edu.au (N.L. Daly).

\section{Abstract}

The Australian big box jellyfish, Chironex fleckeri, belongs to a family of cubozoan jellyfish that are known for their potent venoms. C. fleckeri toxin 1 (CFTX-1) is a cardiotoxic and hemolytic protein that is potentially responsible for the rapid cardiovascular collapse in human envenomation victims. Based on secondary structure analysis of CfTX-1, previous studies have predicted several helical regions and concluded that this toxin is a pore-forming toxin.

We synthesized two putative helical regions (CfTX- $1_{42-67}$ and CfTX $_{93-120}$ ) from CfTX-1 and conducted a structural analysis with nuclear magnetic resonance (NMR) spectroscopy. CfTX-1 $1_{42-67}$ does not form a structure in aqueous solution, but does form a helical structure in the presence of SDS. CfTX $_{93-120}$ is relatively hydrophobic and aggregates in aqueous solution, but forms a helical structure in the presence of SDS, consistent with the structure of this region in the CfTX-1 model predicted using I-TASSER. Our results are also consistent with residues 93-120 in CfTX-1 being involved in membrane-spanning. This study confirms the presence of helical regions in CfTX-1 derived peptides, providing the first experimental structure information relating to this protein, and insight into its function.

Keywords: Chironex fleckeri venom, CfTX-1, Cubozoan toxins, Pore forming toxins, NMR

147

GUIDING ANTIVENOM DEVELOPMENT THROUGH LINEAR VISUALIZATION OF VENOMICS DATA

Søren H. Dam ${ }^{\text {a,b,* }}$, Rasmus U.W. Friis ${ }^{\mathrm{a}, \mathrm{b}}$, Andreas H. Laustsen ${ }^{\mathrm{a}}$. ${ }^{\mathrm{a}}$ Department of Bio and Health Informatics, Technical University of Denmark, KongensLyngby, Denmark; ${ }^{\mathrm{b}}$ Department of Biotechnology and Biomedicine, Technical University of Denmark, KongensLyngby, Denmark

* Corresponding author.

E-mail address: soren.helweg@gmail.com (S.H. Dam).

\section{Abstract}

Snakebite is a serious public health issue in many tropical countries affecting primarily poor agricultural workers. The severity of a snakebite is related to the amount of venom injected and its composition of toxins.

To help guide clinicians in predicting development of envenoming, we have developed a linear visualization tool, which will be freely available at tropicalpharmacology.com, for better display of venomics data. The tool can also provide venom and antivenom researchers with an intuitive overview of venom compositions and the amount of toxins likely to be injected by various venomous snakes.

The advantage of this illustration method, compared to the standard pie chart, is that it allows for easy, quantitative comparisons between snake venom proteomes. Another benefit is the facility of fast identification of the toxins with the highest medical relevance for a given envenoming in correlation with their absolute abundance.

Here, some of the functionalities and areas of application will be presented, including inter-/intraspecies venom comparisons and quick elucidation of which toxin families may be critical in a given envenoming case. Finally, future possibilities and features will be discussed.

Keywords: Visualization tool, Antivenom development, Venomics, Toxicovenomics

A DEMONSTRATION OF VARIATION IN VENOM COMPOSITION OF DABOIA RUSSELII (RUSSELL'S VIPER), A SIGNIFICANTLY IMPORTANT SNAKE OF MYANMAR, BY TANDEM MASS SPECTROMETRY 